\title{
ANALISIS KERENTANAN KAWASAN PERMUKIMAN \\ PADA KAWASAN RAWAN BANJIR \\ DI BAGIAN HILIR SUNGAI SARIO
}

\author{
Ivone Paula Bungkolu \\ Grace A. J. Rumagit \\ Rine Kaunang
}

\begin{abstract}
The objectives of this research are: (1) Analyzing any susceptibility factors that can influence people downstream of Sario River to settle or not stay in settlements located in flood prone areas, (2) Reviewing the policy of flood-prone settlement management what is most effective in overcoming the existing flood problems at the site. This research was conducted in September until November 2017. Sampling method used was purposive sampling method. Analytical technique used in this research using quantitative method that is using logistic regression. The results of this study indicate that (1) the most influencing factor of the person staying in the flood prone area downstream of the Sario River is the social susceptibility factor precisely the social ties, ie the close kinship between the members of the community in the location. (2) Furthermore, the most appropriate government program for dealing with settlements of the lower flood prone areas of the Sario River is through the creation of a retaining river basin or river dredging.
\end{abstract}

Keywords: the vulnerability analysis, settlement, flooding, downstream sario river, Manado City

\begin{abstract}
ABSTRAK
Tujuan dari penelitian ini adalah (1) Menganalisa faktor-faktor kerentanan apa saja yang dapat mempengaruhi masyarakat yang berada di bagian hilir Sungai Sario untuk menetap atau tidak menetap tinggal di pemukiman yang terletak pada kawasan rawan banjir, (2) Mengkaji kebijakan penanganan permukiman rawan banjir apa yang paling efektif dalam mengatasi permasalahan banjir yang ada di lokasi tersebut. Penelitian ini dilaksanakanan pada bulan September hingga November 2017. Metode pengumpulan sampel yang digunakan adalah metode purposive sampling. Teknik analisis yang digunakan pada penelitian ini menggunakan metode kuantitatif yaitu menggunakan regresi logistik. Hasil penelitian ini menunjukkan bahwa (1) faktor penyebab yang paling mempengaruhi seseorang tetap bermukim di kawasan rawan banjir bagian hilir Sungai Sario adalah faktor kerentanan sosial tepatnya ikatan sosial, yaitu adanya hubungan kekerabatan yang erat antara anggota masyarakat yang ada dalam lokasi tersebut. (2) Selanjutnya program pemerintah yang paling tepat untuk menangani permukiman kawasan rawan bajir bagian Hilir Sungai Sario adalah dengan pembuatan talud penahan sungai atau pengerukan sungai.
\end{abstract}

Kata kunci: analisis kerentanan, pemukiman, banjir, Kelurahan Sario, Kota Manado 


\section{PENDAHULUAN}

\section{Latar Belakang}

Kota Manado dilalui kurang lebih 21 sungai, 5 (lima) diantaranya adalah sungai besar yang melintasi wilayah Kota Manado, yaitu Sungai Malalayang, Sungai Sario, Sungai Tikala, Sungai Tondano, dan Sungai Bailang. Kelima sungai tersebut berpotensi besar terhadap bencana banjir di Kota Manado, termasuk didalamnya adalah yang menjadi objek penelitian yaitu Sungai Sario. Dirjen Penataan Ruang Kementerian PU tahun 2014 menetapkan kawasan di bagian hilir Sungai Sario masuk dalam kategori Red Area (Banjir Tinggi) di Kota Manado (lihat Gambar 1).

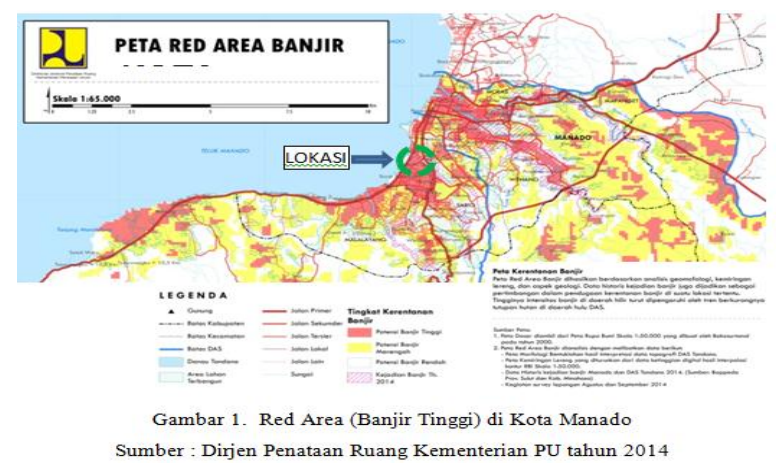

Demikian halnya dalam arahan Rencana Tata Ruang Kota Manado 2014-2034 mengarahkan kawasan rawan banjir salah satunya adalah kawasan permukiman yang terletak di bagian hilir Sungai Sario, yang meliputi beberapa kelurahan yaitu Kelurahan Sario Utara, Kelurahan Titiwungen Selatan, Kelurahan Sario Kotabaru, Kelurahan Tanjung Batu, Kelurahan Wanea, Kelurahan Ranotana, Kelurahan Pakowa dan Kelurahan Ranotana Weru. Berdasarkan Perda No. 1 tahun 2014 tentang RTRW Kota Manado 2014-2034, mengarahkan kawasan bagian hilir Sungai Sario sebagai sungai besar di dalam kawasan permukiman yang memiliki talud, maka sempadan sungai diarahkan sejauh 5 meter dikanan-kiri badan sungai. Eksisting yang ada saat ini terlihat bahwa kawasan sempadan sungai sudah dipenuhi dengan bangunan rumah, bahkan ada permukiman yang sudah memanfaatkan badan sungai sehingga mempersempit lebar sungai (lihat gambar 2).

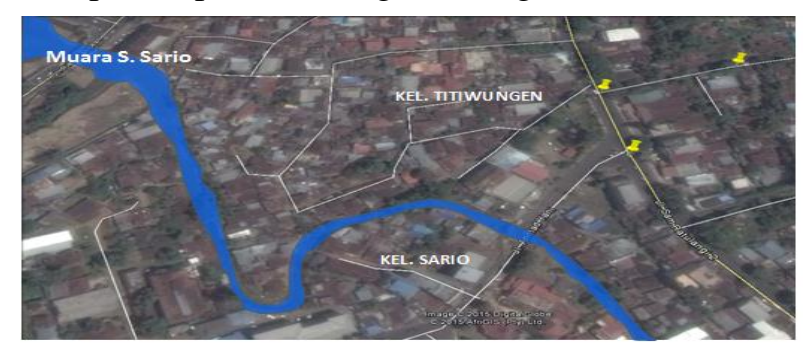

Gambar 2. Kondisi Eksisting Permukiman Rawan Banjir di Bagian Hilir Sungai Sario
Dan jika merujuk dari catatan kejadian banjir besar yang melanda Kota Manado, yang terjadi pada tanggal 03 Desember 2000, tanggal 21 Februari 2006, tangga 17 Februari 2013 dan tanggal 15 Januari 2014, maka wilayah bagian hilir Sungai Sario tidak pernah luput dari musibah bencana banjir bandang tersebut, bahkan wilayah bagian hilir Sungai Sario ini merupakan wilayah yang cukup parah terlanda banjir bandang. Berdasarkan hasil laporan banjir Kota Manado tahun 2014, Pos AWLR mencatat bahwa tingginya air Sungai Sario pada waktu terjadi banjir bandang tanggal 15 Januari 2014 mencapai $\pm 5-6 \mathrm{~m}$. Peristiwa banjir pada bagian hilir Sungai Sario ini, bukan hanya dialami masyarakat pada 4 (empat) kejadian banjir bandang di atas saja, tetapi musibah banjir ini rutin dialami masyarakat, dimana setiap tahun masyarakat mengalami musibah banjir tahunan.

Dari beberapa kelurahan yang masuk dalam wilayah hilir Sungai Sario, permukiman di Kelurahan Sario Utara dan Kelurahan Titiwung Selatan adalah daerah yang mengalami dampak paling parah bila terjadi banjir karena kedua kelurahan ini, selain berada di daerah bantaran Sungai Sario bagian hilir, juga terletak di pesisir pantai (Teluk Manado). Jika terjadi curah hujan yang tinggi dibarengi dengan naiknya permukaan air laut (terjadi air pasang laut), maka aliran sungai ke laut menjadi lambat, dan terjadi aliran balik (back water) ke sungai, sehingga air sungai meluap menyebabkan bencana banjir bagi wilayah permukiman yang berada di bantaran sungai tersebut. Sehingga dapat disimpulkan bahwa kawasan permukiman di bagian hilir Sungai Sario sangat rentan mengalami musibah banjir. Tingginya kerentanan terhadap musibah banjir di kawasan tersebut, tidak serta merta membuat masyarakat pada kawasan banjir tersebut meninggalkan atau berpindah dari tempat tersebut, bahkan rencana program pemerintah untuk merelokasi rumah-rumah yang berada di bantaran sungai tersebut tidak mendapat respon yang baik dari masyarakat setempat. Masyarakat sepertinya sudah beradaptasi dengan kondisi banjir yang mereka alami rutin setiap tahunnya, hal ini terlihat dari bagaimana masyarakat mengatasi musibah banjir jika musim penghujan datang. Terdapat upaya yang dilakukan oleh masyarakat untuk bertahan dari banjir yaitu dengan cara meninggikan rumah mereka, baik dengan menimbun maupun membuat rumah dengan tipe panggung, tetapi tentunya hal ini hanya bisa dilakukan oleh masyarakat yang mempunyai tingkat ekonomi yang tinggi. Bagi masyarakat yang rentan ekonominya bentuk antisipasi tersebut tidak mungkin mereka lakukan karena mahalnya biaya. Mereka hanya dapat pasrah bila rumah mereka 
kebanjiran. Dan kerentanan erat kaitannya dengan kerugian atau resiko. Menurut Wignyosukarto (2009), kerugian atau resiko atas terjadinya bencana tergantung pada daya tahan manusia, lingkungan, dan infrastruktur yang ada, semakin besar bencana yang terjadi, maka kerugian akan semakin besar apabila manusia, lingkungan, dan infrastruktur yang ada semakin rentan. Masih menurut Wignyosukarto (2009), kerentanan adalah suatu keadaan penurunan ketahanan akibat pengaruh eksternal yang mengancam kehidupan, mata pencaharian, sumber daya alam, infrastruktur, produktivitas ekonomi, dan kesejahteraan. Kerentanan sosial misalnya, adalah sebagian dari produk kesenjangan sosial, yaitu faktor sosial yang mempengaruhi atau membentuk kerentanan berbagai kelompok dan yang juga mengakibatkan penurunan kemampuan untuk menghadapi bencana seperti, bencana kekeringan, bencana banjir, degradasi kualitas air, dan lain sebagainya. Sehingga tetap bermukimnya masyarakat di kawasan rawan bencana dapat disebabkan beberapa hal, yang pertama mereka mampu mengantisipasi kerawanan terhadap bencana sehingga mereka tetap bertahan dan tetap bermukim. Hal kedua yang menyebabkan seseorang tetap bertahan tinggal di lokasi kawasan rawan bencana adalah berkaitan erat dengan faktor-faktor kerentanan yang melekat pada masing-masing individu. Faktor-faktor kerentanan yang dimaksud adalah kerentanan sosial, ekonomi, fisik terbangun, dan kelembagaan. Kerentanan suatu sistem (sosial, ekonomi, lingkungan terbangun, dan program pemerintah) dalam masyarakat yang berada pada daerah rawan bencana akan berpengaruh kepada keputusan seseorang untuk bermigrasi atau tidak bermigrasi (Macchi dalam Pratiwi, 2009).

Penelitian ini dilakukan untuk mengkaji faktor-faktor kerentanan apa saja yang berpengaruh terhadap keputusan masyarakat yang tinggal di bagian hilir Sungai Sario, yaitu Kelurahan Sario Utara dan Kelurahan Titiwungen Selatan untuk menetap atau tidak menetap. Sehingga diharapkan penelitian ini dapat membantu Pemerintah Kota Manado dalam menentukan kebijakan apa yang paling efektif dalam menangani permasalahan permukiman di kawasan rawan banjir tersebut.

\section{Rumusan Masalah}

Kelurahan Sario Utara dan Kelurahan Titiwungen Selatan yang berada di hilir Sungai Sario merupakan daerah rawan bencana banjir terutama pada saat musim penghujan, dan musibah banjir rutin dialami masyarakat setiap tahunnya. Fenomena tetap bermukimnya masyarakat di daerah rawan banjir diindikasikan sangat erat dengan kerentanan yang melekat pada masing-masing individu yang ada di kelurahan tersebut. Berdasarkan rumusan masalah yang ada, maka secara spesifik permasalahan tersebut dapat dirumuskan menjadi suatu pertanyaan penelitian, yaitu :

1. Faktor - faktor kerentanan yang paling mempengaruhi keputusan masyarakat yang berada di bagian hilir Sungai Sario untuk tetap bermukim atau tidak pada kawasan rawan banjir tersebut.

2. Kebijakan penanganan permukiman rawan banjir yang paling efektif dalam mengatasi permasalahan banjir yang ada di bagian hilir Sungai Sario tersebut.

\section{Tujuan Penelitian}

Tujuan dari penelitian ini adalah untuk menjawab permasalahan yang dirumuskan di atas, yaitu :

1. Menganalisa faktor-faktor kerentanan yang dapat mempengaruhi masyarakat yang berada di bagian hilir Sungai Sario untuk tetap bermukim pada kawasan rawan banjir tersebut atau tidak menetap.

2. Mengkaji kebijakan penanganan permukiman rawan banjir yang paling efektif dalam mengatasi permasalahan banjir yang ada di lokasi tersebut.

\section{Manfaat Penelitian}

Manfaat dari penelitian ini adalah

1. Sebagai bahan informasi mengenai faktor-faktor kerentanan yang dapat mempengaruhi keputusan masyarakat dibagian hilir sungai Sario untuk tetap bermukim pada kawasan rawan banjir,

2. Sebagai informasi baik bagi Pemerintah Kota Manado maupun semua pihak yang terkait dalam pembangunan di Kota Manado lebih khusus di kawasan bantaran Sungai Sario.

\section{METODOLOGI PENELITIAN}

\section{Waktu dan Lokasi Penelitian}

Waktu penelitian direncanakan selama 3 (tiga) bulan, dimulai sejak awal September 2017 dan berakhir pada bulan November 2017.

Lokasi Penelitian terletak di wilayah Kelurahan Sario Utara Lingkunagn 1, 2 dan 3 dan Kelurahan Titiwungen Selatan Lingkunagn 1 dan 2 Kecamatan Sario, tepatnya permukiman yang berada di kawasan rawan banjir Sungai Sario Kota Manado. Lokasi penelitian merupakan wilayah Daerah Aliran Sungai (DAS) Sario di bagian hilir, seperti terlihat pada Gambar 3. 


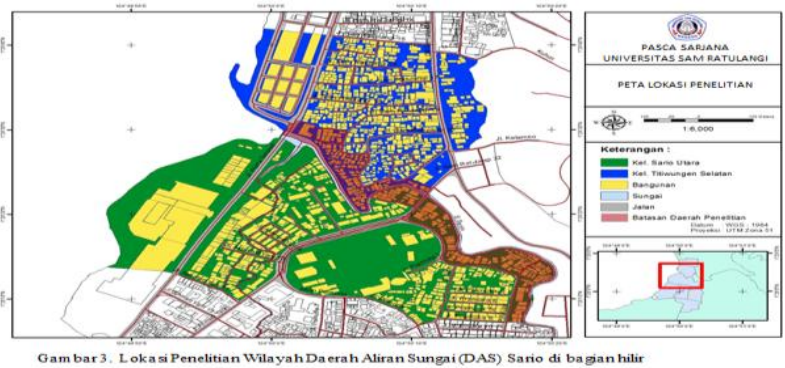

\section{Jumlah Sampel Yang Digunakan}

Teori Sampel dan Sampling Penelitian menurut Arikunto (2010: 134-185), yaitu sampel adalah sebagian atau wakil populasi yang diteliti. Berdasarkan pengertian di atas, dapat disimpulkan sampel adalah bagian populasi yang hendak diteliti dan mewakili karakteristik populasi. Apabila populasi penelitian berjumlah kurang dari 100, maka sampel yang dambil adalah semuanya. Namun apabila populasi penelitian berjumlah lebih dari 100, maka sampel dapat diambil antara $10-15 \%$ atau 20$25 \%$, atau lebih.

\section{Metode Pengumpulan Sampel}

Metode pengumpulan sampel dalam penelitian ini adalah dengan menggunakan metode purposive sampling, merupakan teknik samping secara nonprobabilitas, yaitu teknik pengambilan sample yang ditemukan atau ditentukan sendiri oleh peneliti atau menurut pertimbangan pakar. Sugiyono (2001: 61) menyatakan bahwa sampling purposive adalah teknik penentuan sampel dengan pertimbangan tertentu. Menurut Margono (2004:128), pemilihan sekelompok subjek dalam purposive sampling didasarkan atas ciri-ciri tertentu yang dipandang mempunyai sangkut paut yang erat dengan ciri-ciri populasi yang sudah diketahui sebelumnya, dengan kata lain unit sampel yang dihubungi disesuaikan dengan kriteria-kriteria tertentu yang diterapkan berdasarkan tujuan penelitian. Tahapan pengambilan sampel di wilayah permukiman bagian hilir Sungai Sario Kelurahan Sario Utara dan Kelurahan Titiwungen Selatan adalah sebagai berikut :

1. Menghitung jumlah rumah yang berada di kawasan rawan banjir Kelurahan Titiwungen, terletak di Lingkungan 1 dan 2 dengan jumlah rumah sebanyak 87 rumah, sedangkan Kelurahan Sario Utara terletak di Lingkungan 1, 2 dan 3 dengan jumlah rumah sebanyak 113 rumah. Jadi total rumah yang berada di kawasan rawan bajir Sungai Sario pada lokasi penelitian berjumlah 200 rumah.

2. Menetapkan jumlah sampel, diambil $25 \%$ dari total populasi rumah di kawasan rawan bajir bagian hilir Sungai Sario, maka jumlah sample yang didapat adalah berjumlah 50 sampel.

3. Sampel ini diedarkan pada kedua kelurahan yang menjadi obyek penelitian, dimana tidak ada pembagian secara proporsional jumlah sample untuk masing-masing kelurahan tersebut, karena dianggap semua unit sampel yang ditemui di lokasi penelitian mempunyai ciri-ciri yang sesuai dengan kriteria yang ditetapkan berdasarkan tujuan penelitian, yaitu masyarakat yang terkena dampak dari bencana banjir di bagian hilir Sungai Sario.

\section{Peubah/Variabel Yang Digunakan dan Definisi Operasionalnya}

Dalam penelitian ini terdapat 1 variabel dependen, dan 8 variabel independen yang meberi pengaruh terhadap keputusan tetap bermukimnya masyarakat di kawasan rawan banjir atau tidak. Variabel Dependen sering disebut sebagai variable ouput, kriteria konsekuensi. Dalam bahasa Indonesia disebut variable terikat, merupakan variable yang dipengaruhi atau yang menjadi akibat, karena adanya variabel bebas. Variable dependen dalam penelitian ini adalah keputusan tetap bermukim atau tidak masyarakt di bagian hilir Sungai Sario yang merupakan kawasan rawan banjir, dimana nilai dari variable ini (Y) dapat dibedakan menjadi dua kategori, yaitu "Tetap Bermukim"atau "Pindah/Relokasi", dinotasikan $\mathrm{Y}=$ 1 (Tetap bermukim) dan $\mathrm{Y}=0$ (Pidah/Relokasi). Sedangkan variable Independen sering disebut variable stimulus, predictor, antecedent. Dalam bahasa Indonesia disebut variable bebas adalah variable yang mempengaruhi atau menjadi penyebab perubahannya atau timbulnya variable dependen (terikat). Peubah atau variable independen/bebas yang diamati dalam penelitian ini adalah factorfaktor kerentanan yang mempengaruhi keputusan masyarakat yang bermukim di kawasan rawan banjir untuk tetap bermukim atau pindah/relokasi. Peubah/variabel independen yang diukur tersebut adalah :

a. Kerentanan Sosial :

1) Tingkat Pendidikan

2) Ikatan Sosial

3) Interaksi Sosial

b. Kerentanan ekonomi :

4) Mata pencaharian

5) Tingkat pendapatan

6) Lokasi pekerjaan

c. Kerentanan lingkungan :

7) Jenis rumah : (Rumah panggung/Rumah bertingkat/Rumah bukan bentuk panggung atau bertingkat) 
d. Kerentanan program :

8) Ada tidaknya bentuk program pemerintah di kawasan rawan banjir Pengkategorian peubah/variabel dependen dan indepen yang akan diteliti dapat dilihat lebih jelas pada Tabel 1, berikut ini.

\begin{tabular}{|c|c|c|c|}
\hline Faktor & & Ketegori Data & Data \\
\hline \multirow[t]{3}{*}{$\begin{array}{l}\text { a. Kerentanan } \\
\text { social }\end{array}$} & 1) & $\begin{array}{l}\text { Tingkat } \\
\text { pendidikan }\end{array}$ & $\begin{array}{l}1=\text { Tidak tamat SD } \\
2=\text { Tamat SD } \\
3=\text { Tamat SMP } \\
4=\text { Tamat SMA } \\
5=\text { Tamat Perguruan Tinggi }\end{array}$ \\
\hline & 2) & Ikatan Sosial & $\begin{array}{l}1=\text { Tidak AdaKerabat } \\
2=\text { Ada Kerabat }\end{array}$ \\
\hline & 3) & Interaksi Sosial & $\begin{array}{l}1=\text { Tidak Ada Kegiatan } \\
\text { Kemasyarakatan } \\
2=\text { Ada Kegiatan } \\
\text { Kemasyarakatan }\end{array}$ \\
\hline \multirow[t]{3}{*}{$\begin{array}{l}\text { b. Kerentanan } \\
\text { Ekonomi }\end{array}$} & 4) & Mata pencaharian & $\begin{array}{l}1=\text { PNS } \\
2=\text { Karyawan Swasta } \\
3=\text { Wiraswasta } \\
4=\text { Nelayan } \\
5=\text { Sopir } \\
6=\text { Buruh } \\
7=\text { Pembantu Rumah } \\
\text { Tangga }\end{array}$ \\
\hline & 5) & $\begin{array}{l}\text { Tingkat } \\
\text { pendapatan }\end{array}$ & $\begin{array}{l}1=<\text { Rp. } 500.000 \\
2=500.000-1.000 .000 \\
3=1.000 .000-2.000 .000 \\
4=>2.000 .000\end{array}$ \\
\hline & 6) I & okasi pekerjaan & $\begin{array}{l}1=\text { Bekerja di Luar/Jauh } \\
\text { dari Lokasi Rawan Bajir } \\
2=\text { Bekerja di } \\
\text { Lokasi/Dekat Rawan } \\
\text { banjir }\end{array}$ \\
\hline \multirow{2}{*}{$\begin{array}{l}\text { c. Kerentanan } \\
\text { Lingkungan }\end{array}$} & \multirow{2}{*}{\multicolumn{2}{|c|}{ 7) Jenis Rumah }} & $1=$ Rumah panggung \\
\hline & & & $\begin{array}{c}3=\text { Rumah bukan bentuk } \\
\text { panggung atau } \\
\text { bertingkat }\end{array}$ \\
\hline $\begin{array}{l}\text { d. Kerentanan } \\
\text { Program }\end{array}$ & 8) & $\begin{array}{l}\text { Ada tidaknya } \\
\text { bentuk program } \\
\text { pemerintah di } \\
\text { kawasan rawan } \\
\text { banjir }\end{array}$ & $\begin{array}{l}1=\text { Tidak Ada Program } \\
\text { Pemerintah } \\
2=\text { Ada Program } \\
\quad \text { Pemerintah }\end{array}$ \\
\hline $\begin{array}{l}\text { e. Keputusan } \\
\text { Masyarakat }\end{array}$ & 9) & $\begin{array}{l}\text { Keputusan } \\
\text { Relokasi/Pindah } \\
\text { atau Tetap Menetap }\end{array}$ & $\begin{array}{l}1=\text { Relokasi } / \text { Pindah } \\
2=\text { Tetap Menetap }\end{array}$ \\
\hline
\end{tabular}

\begin{abstract}
Variabel-variabel tersebut ditambah dengan karakteristik dan sejarah bermukimnya masyarakat serta karakteristik banjir di wilayah bagian hilir DAS Sario, merupakan factor-faktor yang berinteraksi dalam pengambilan keputusan kepada masyarakat untuk tetap bermukim atau tidak di kawasan rawan banjir.
\end{abstract}

\section{Teknik Pengumpulan Data}

Data merupakan sejumlah informasi yang dapat memberikan gambaran tentang suatu keadaan (Sugiarto, 2006) dan di kelompokkan berdasarkan homoginitas data (Prakarsa, 2006). Pengumpulan data adalah prosedur yang sistimatis dan standar untuk memperoleh data yang diperlukan (Nasir,
2003). Ada dua teknik pengumpulan data yang digunakan dalam penelitian ini yaitu teknik pengumpulan data primer dan teknik pengumpulan data sekunder.

1) Teknik pengumpulan data primer

a. Observasi Lapangan

Teknik ini digunakan untuk mengumpulkan data yang dilakukan melalui pengamatan dan pencatatan data yang tampak pada objek penelitian (Nawawi, 2006). Observasi lapangan bertujuan agar peneliti memperoleh fakta dari wilayah studi yaitu Kelurahan Sario Utara dan Kelurahan Titiwungen Selatan serta untuk melengkapi data yang tidak dapat diperoleh dari telaah dokumen, studi literatur, kuesioner, maupun wawancara. Observasi lapangan dilakukan dengan dokumentasi gambar di lapangan untuk memperkuat fakta yang ditemukan serta membuat catatancatatan penting yang harus segera ditulis setelah mengamati keadaan dan kejadian di wilayah studi.

b. Kuesioner

Adalah data primer yang digunakan untuk melengkapi data-data skunder. Pertanyaanpertanyaan dalam kuesioner ini disusun berdasarkan identifikasi factor-faktor kerentanan masyarakat yang berada di kawasan rawan banjir. Kuisinor ini akan dijalankan kepada 50 responden, dengan komposisi 22 responden di Kelurahan Titiwungen Selatan dan 28 responden di Kelurahan Sario Utara. Semua responden ini berada di lokasi rawan banjir bagian hilir Sungai Sario. Sehingga hasil dari kuisioner ini akan didapatkan data primer dari masyarakat yang bermukim di kawasan rawan banjir Sungai Sario.

c. Wawancara

Dilakukan melalui kontak dalam bentuk tatap muka langsung antara peneliti dengan responden, dimana responden yang diwawancarai. Wawancara dilakukan kepada beberapa responden yang dipandang perlu untuk mengorek sedalam-dalamnya seluruh informasi langsung sesuai dengan tujuan penelitian. Dimana responden yang 
diwawancarai adalah Lurah Kelurahan Sario Utara dan Titiwungen Selatan, Kepala Lingkungan 1, 2 dan 3 di Kelurahan Sario Utara, Kepala Lingkungan 1 dan 2 Kel. Titiwungen Selatan, serta beberapa masyarakat yang tinggal dalam wilayah bantaran Sungai Sario, yaitu di area $15 \mathrm{~m}$ dari sungai.

2) Teknik pengumpulan data sekunder

Teknik pengumpulan data sekunder hanya menggunakan telaah dokumen. Telaah dokumen yang dimaksud adalah salah satu cara untuk mendapatkan imformasi pendukung melalui berbagai sumber. Informasi data sekunder didapatkan dari dokumen-dokumen, yaitu Kecamatan Sario Dalam Angka dan Manado Dalam Angka data statistik dari BPS, RPJMD Kota Manado, RTRW Kota Manado, jurnal, studi-studi dan peta dari Dinas PUPR dan Bapelitbang Kota Manado, serta data hasil survey dari Program Kotaku untuk Kecamatan Sario.

Identifikasi data-data yang akan dibutuhkan dalam penelitian ini dapat dilihat pada Tabel 2.

\section{Teknik Analisis Yang Digunakan}

Berdasarkan pertanyaan penelitian yang dirumuskan pada bagian awal penulisan ini adalah : "Faktor - faktor kerentanan apa saja yang paling mempengaruhi keputusan masyarakat yang berada di bagian hilir Sungai Sario untuk tetap bermukim atau tidak pada kawasan rawan banjir tersebut", maka analisis yang digunakan pada penelitian ini adalah menggunakan Analisis Regresi Logistik. Menurut Duwi Priyatno (2013), Regresi Logistik adalah analisis untuk memperkirakan suatu hasil berdasarkan pada perubahan nilainilai variabel independen. Atau untuk memperkirakan kemungkinan/kecenderungan (odds) berdasarkan masing-masing nilai variabel independen. Analisis ini sebenarnya sama dengan Regresi Linier, hanya saja variabel dependen yang digunakan adalah dikotomi.

\begin{tabular}{|c|c|c|c|}
\hline Kategori & $\begin{array}{c}\text { Kebutuhan } \\
\text { Data }\end{array}$ & Tahun & $\begin{array}{c}\text { Sumber } \\
\text { data }\end{array}$ \\
\hline $\begin{array}{l}\text { Mengidentifikasi } \\
\text { karakteristik \& } \\
\text { sejarah } \\
\text { bermukimnya } \\
\text { masyarakat di } \\
\text { bagian hilir DAS } \\
\text { Sario }\end{array}$ & $\begin{array}{l}\text { Jumlah } \\
\text { penduduk } \\
\text { Jumlah KK } \\
\text { Usia } \\
\text { Agama } \\
\text { Lama } \\
\text { bermukim } \\
\text { Etnis }\end{array}$ & 2017 & $\begin{array}{l}\text { Kantor } \\
\text { Kelurahan } \\
\text { Kuisioner }\end{array}$ \\
\hline $\begin{array}{l}\text { Mengidentifikasi } \\
\text { karakteristik banjir } \\
\text { di wilayah penelitian }\end{array}$ & $\begin{array}{l}\text { Tinggi } \\
\text { genangan } \\
\text { Lama } \\
\text { genangan } \\
\text { Frekuensi } \\
\text { terjadinya } \\
\text { banjir }\end{array}$ & $\begin{array}{l}5 \text { thn } \\
\text { terakhir }\end{array}$ & $\begin{array}{l}\text { Kantor } \\
\text { Kelurahan } \\
\text { Balai } \\
\text { Wilayah } \\
\text { Sungai } \\
\text { (Sulut) }\end{array}$ \\
\hline $\begin{array}{l}\text { Faktor kerentanan } \\
\text { sosial terhadap } \\
\text { menetapnya } \\
\text { masyarakat di } \\
\text { kawasan rawan } \\
\text { bencana banjir }\end{array}$ & $\begin{array}{l}\text { Tingkat } \\
\text { pendidikan } \\
\text { Ikatan Sosial } \\
\text { Interaksi } \\
\text { Sosial }\end{array}$ & 2017 & Kuisioner \\
\hline $\begin{array}{l}\text { Faktor kerentanan } \\
\text { ekonomi terhadap } \\
\text { menetapnya } \\
\text { masyarakat di } \\
\text { kawasan rawan } \\
\text { bencana banjir }\end{array}$ & $\begin{array}{l}\text { Mata } \\
\text { pencaharian } \\
\text { Tingkat } \\
\text { pendapatan } \\
\text { Lokasi } \\
\text { pekerjaan }\end{array}$ & 2017 & Kuisioner \\
\hline $\begin{array}{l}\text { Faktor kerentanan } \\
\text { lingkungan } \\
\text { terbangun terhadap } \\
\text { menetapnya } \\
\text { masyarakat di } \\
\text { kawasan rawan } \\
\text { bencana banjir }\end{array}$ & $\begin{array}{l}\text { Rumah } \\
\text { panggung } \\
\text { Rumah } \\
\text { bertingkat } \\
\text { Rumah bukan } \\
\text { bentuk } \\
\text { panggung } \\
\text { atau } \\
\text { bertingkat }\end{array}$ & 2017 & $\begin{array}{l}\text { Kuisioner } \\
\text { Observasi }\end{array}$ \\
\hline $\begin{array}{l}\text { Faktor kerentanan } \\
\text { program } \\
\text { terbangun } \\
\text { terhadap } \\
\text { menetapnya } \\
\text { masyarakat di } \\
\text { kawasan rawan } \\
\text { bencana banjir }\end{array}$ & $\begin{array}{l}\text { Ada tidaknya } \\
\text { bangunan } \\
\text { tanggul banji } \\
\text { Ada tidaknya } \\
\text { bangunan } \\
\text { rumah pompa } \\
\text { untuk } \\
\text { menanggulan } \\
\text { gi banjir }\end{array}$ & 2017 & $\begin{array}{l}\text { Kuisioner } \\
\text { Observasi }\end{array}$ \\
\hline $\begin{array}{l}\text { Bentuk antisipasi } \\
\text { masyarakat untuk } \\
\text { bertahan dari } \\
\text { bencana banjir } \\
\text { kaitannya dengan } \\
\text { keputusan tetap } \\
\text { bermukimnya } \\
\text { masyarakat di } \\
\text { kawasan rawan } \\
\text { bencana banjir }\end{array}$ & $\begin{array}{l}\text { Ada tidaknya } \\
\text { bentuk } \\
\text { antisipasi } \\
\text { yang } \\
\text { dilakukan } \\
\text { masyarakat }\end{array}$ & 2017 & $\begin{array}{l}\text { Kuisioner } \\
\text { Observasi }\end{array}$ \\
\hline
\end{tabular}

Regresi logistik membentuk persamaan atau fungsi dengan pendekatan maximum likelihood, yang memaksimalkan peluang pengklasifikasian objek yang diamati menjadi kategori yang sesuai kemudian mengubahnya menjadi koefisien regresi yang sederhana. Dua nilai yang biasa digunakan sebagai variabel dependen yang diprediksi adalah 0 dan 1 (ex. 1=berhasil, 0=gagal). Regresi logistik akan membentuk variabel preditor/respon $(\log (\mathrm{p} /(1-\mathrm{p})$ 
yang merupakan kombinasi linier dari variabel independen (Menurut Ariyoso, 2016) Data yang digunakan variable dependen (Y) adalah dikotomi (dummy variable), sedangkan variable independen (X) adalah bertipe interval atau rasio (scale), jika variable independen adalah kategori, maka perlu diubah ke bentuk numerik dengan memberi value, misalnya 1 = tidak baik, 2 = baik, 3 = sangat baik, sehingga mudah untuk mengintepretasi hasil analisisnya. Bila variable independen (predictor) 3 (tiga) kategori atau lebih, maka dibuat dua category, caranya dengan membuat dummy variable, kategori ulang sesuai logika biologik. Untuk variable independen/predator yang lebih dari dua atau banyak variable menggunakan regresi logistik ganda (multiple regression logistic).

Variabel-variabel yang digunakan dalam penelitian ini adalah sebagai berikut:

1) Tetap bermukimanya masyarakat atau tidak, dirumuskan sebagai variable dependen atau (Y), sedangkan faktor-faktor yang mempengaruhi masyarakat untuk tetap bermukim atau tidak dirumuskan sebagai variable independen (X).

2) Banyaknya variabel independen (X) yang akan mempengaruhi variabel dependen (Y), ditentukan oleh 4 faktor kerentanan (menurut Macchi dalam Pratiwi, 2009) :

a) Kerentanan Sosial meliputi tingkat pendidikan (X1), ikatan sosial (X2), dan interaksi sosial (X3)

b) Kerentanan Ekonomi, meliputi : tingkat pendapatan (X4), mata pencaharian (X5) dan lokasi pekerjaan (X6)

c) Kerentanan Lingkungan Terbangun (X7), meliputi : bentuk rumah panggung atau bukan bentuk rumah panggung

d) Kerentanan Program (X8), meliputi : ada atau tidaknya program-program pemerintah yang berkaitan dengan antisipasi maupun mitigasi untuk mengendalikan ataupun mencegah terjadinya bencana.

Seluruh variabel tersebut membangun persamaan logistik ganda dengan model:

$\ln (\mathrm{P} / 1-\mathrm{P})=\alpha+\mathrm{B} 1 \mathrm{X} 1+\mathrm{B} 2 \mathrm{X} 2+\mathrm{B} 3 \mathrm{X} 3+\mathrm{B} 4 \mathrm{X} 4+\mathrm{B} 5 \mathrm{X} 5+\mathrm{B} 6 \mathrm{X} 6+\mathrm{B} 7 \mathrm{X} 7+\mathrm{B} 8 \mathrm{X} 8$ dimana :

$\ln (\mathrm{P} / 1-\mathrm{P})=\log$ odd (logit), Logaritma natural dari Odds. Odds adalah rasio probabilitas suatu peristwa untuk terjadi dan probabilitas untuk tidak terjadi

$\alpha=$ konstanta (intersep)

B1..B8 = koefisien regresi variable independen/ predictor (slope)
$\mathrm{X} 1 \ldots \mathrm{X} 2=$ variable independen/predictor yang pengaruhnya akan diteliti

$\mathrm{P} \quad=$ probabilitas untuk terjadinya "peristiwa" dari variable dependen yang dikotomus

Alat analisisnya akan menggunakan Program SPSS 21. Berikut langkah-langkah analisis dengan menggunakan SPSS 21 (Yamin, Sofyan \& Heri Kurniawan. 2014.).

1) Menyiapkan Data

Langkah awal adalah dengan membuat Kategorisasi Nilai Variabel, menjadi dua kategori, baik variable dependen (Y), maupun variable independen (X). Jika terdapat lebih dari dua kategori pada variable independen/preditor, maka harus diubah menjadi dua kategori dengan dummy variabel. Setelah data siap dalam program exel, buka SPSS Data Editor dan pada tab Variable View(1) buatlah variabel dengan nama masing-masing. Ubah nilai desimal variabel $\mathrm{X} 1 ， \mathrm{X} 2 \ldots . . \mathrm{X} 8$ pada kolom Decimals (2) menjadi 0. Langkah selanjutnya, klik pada bagian baris (Y) dan kolom Values (3), sehingga akan muncul jendela Value Labels. Pada bagian ini kita definisikan kategori Variabel Dependen (Y) berdasarkan data yang kita miliki (4), dimana kategori "perata" kita beri skor 1 dan kategori "bukan perata" kita beri skor 0. Masukkan skor 0 pada bagian Value dan "bukan perata" pada bagian Value Label, lalu klik Add. Lakukan hal yang sama untuk kategori "perata". Klik $O K$. Perlu diperhatikan bahwa pendefinisian skor 1 dan 0 tidak boleh terbalik, skor 1 untuk kategori/peluang sukses dan skor 0 untuk kategori/peluang gagal. Klik pada tab Data View (5), lalu masukkan satu per satu data penelitian sesuai variabelvariabel yang bersangkutan (6). Sebagaimana terlihat pada gambar di atas, variabel independen (X1, X2 .....X8) masing-masing bertipe data metrik, sedangkan variabel Y bertipe data kategorik (binary).

2) Langkah-langkah Estimasi

Klik Analyze > Regression > Binary Logistic, sehingga akan muncul jendela Logistic Regression. Masukkan variabel (X1, $\mathrm{X} 2 \ldots . . \mathrm{X} 8$ ) ke kolom Covariates, sedangkan variabel (Y) ke kolom Dependent. Pada bagian Method paling tidak terdapat 3 opsi yang dapat digunakan, yakni Enter dan Stepwise. Metode Stepwise sendiri terbagi menjadi dua, yakni Forward dan Backward. Pada contoh 
kali ini kita gunakan metode Enter, dimana seluruh variabel prediktor dimasukkan ke dalam model dan diestimasi secara bersamasama. Masih pada jendela Logistic Regression, klik Options, lalu beri tanda checklist pada bagian Classification plots, Hosmer-Lameshow goodnes-of-fit, Correlations of estimates, Iteration history dan $C I$ for $\exp (B)$. Klik Continue. Apabila pada variabel-variabel prediktor terdapat variabel yang bertipe data kategorik, maka kita perlu mendefinisikannya dengan cara klik Categorical, lalu masukkan variabel prediditor bertipe data kategorik tersebut ke kolom Categorical covariates, klik Continue. Namun pada penelitian ini, seluruh variabel prediktor $(\mathrm{X})$ bertipe data metrik. Klik $O K$, maka akan muncul jendela SPSS Viewer yang berisi output hasil estimasi regresi logistik.

3) Output Hasil dan Interpretasi

a. Uji Signifikansi Model

Untuk mengetahui pengaruh variable independen/bebas terhadap variable depeden/terikat secara bersama-sama didalam model.

b. Uji Pasial dan Pembentukan Model Rergresi Logistik

Tujuannya untuk mencari model yang cocok dan keterpautan yang kuat antara model dengan data yang ada atau dengan kata Model FIT dengan Data.

c. Interpretasi Odds Ratio

Merupakan ukuran risiko atau kecenderungan untuk mengalami kejadian "sukses" antara satu kategori dengan kategori lainnya.

Didefiniskan sebagai ratio dari odds untuk $\mathrm{Xj}=1$ terhadap $\mathrm{Xj}=0$. Odds ratio ini menyatakan risiko atau kecenderungan pengaruh observasi $\mathrm{Xj}=1$ adalah berapa kali lipat jika dibandingkan dengan observasi dengan $\mathrm{Xj}=0$. Untuk variable bebas yang berskala kontinyu, maka intrepretasi dari koefisen $\mathrm{Bj}$ pada model regresi logistic adalah setiap kenaikan $C$ unit pada variable bebas akan menyebabkan ratio terjadinya $\mathrm{Y}=1$, adalah exp (C.B) kali lebih besar. Eksponen dari koefisien regresi, yang digunakan untuk mengintepretasikan persamaan logistik yang terbentuk.

\section{HASIL DAN PEMBAHASAN}

\section{Deskripsi Umum Lokasi Penelitian}

1. Wilayah Adminstrasi

Lokasi penelitian kawasan rawan banjir di bagian hilir Sungai Sario secara administrasi terletak pada dua kelurahan, yaitu Kelurahan Sario Utara dan Kelurahan Titiwungen Kecamaan Sario. Adapun batas wilayah penelitian adalah sebagai berikut :

a. Kelurahan Sario Utara meliputi wilayah permukiman bantaran Sungai Sario di Lingkungan 1, 2 dan 3.

b. Kelurahan Titiwungen Selatan meliputi wilayah permukiman bantaran Sungai Sario di Lingkunagn 1 dan 2.

Adapun batas-batas wilayah kedua kelurahan ini adalah :

1) Sebelah Utara berbatasan dengan Kelurahan Wenang

2) Sebelah Selatan dengan Kelurahan Sario Kotabaru dan Keluraha Sario Tumpaan

3) Sebelah Barat dengan Teluk Manado

4) Sebelah Timur dengan Keluraha Tanjung Batu dan Kelurahan Bumi Beringin.

Kelurahan Sario Utara memilki luas wilayah $33 \mathrm{Ha}$ dan Kelurahan Titiwungen Selatan seluas 19,23 Ha. Kelurahan Sario Utara dan Kelurahan Titiwungen ini merupakan daerah dengan wilayah datar karena berada di bagian hilir Sungai Sario.

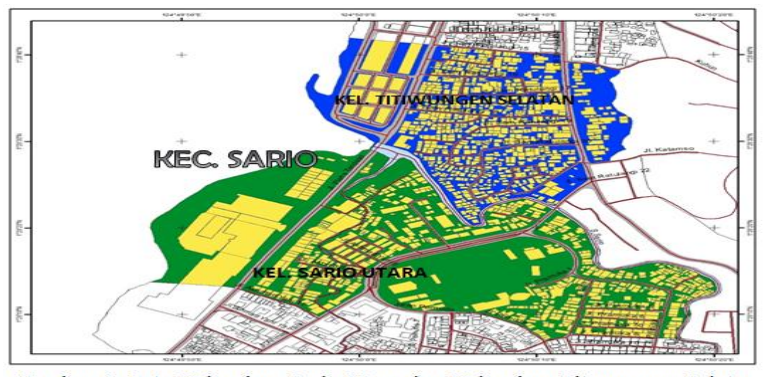

Gambar 4. Peta Kelurahan Sario Utara dan Kelurahan Tituwungen Selatan

2. Jumlah Penduduk

Jumlah penduduk di Kelurahan Sario Utara berjumlah 3.500 jiwa yang terdistribusi di 5 lingkungan, sedangkan penduduk di Kelurahan Titiwungen Selatan berjumlah 3.346 yang terdistribusi di 5 lingkungan. Namun total jumlah penduduk yang berada di kawasan rawan bajir Sungai Sario bagian hilir berjumlah kurang lebih 778 jiwa, yang tersebar di Kelurahan Sari Utara sebanyak 473 jiwa dan Kelurahan Titiwungen 
Selatan sebanyak 305 jiwa. Berikut Tabel 3 jumlah penduduk.

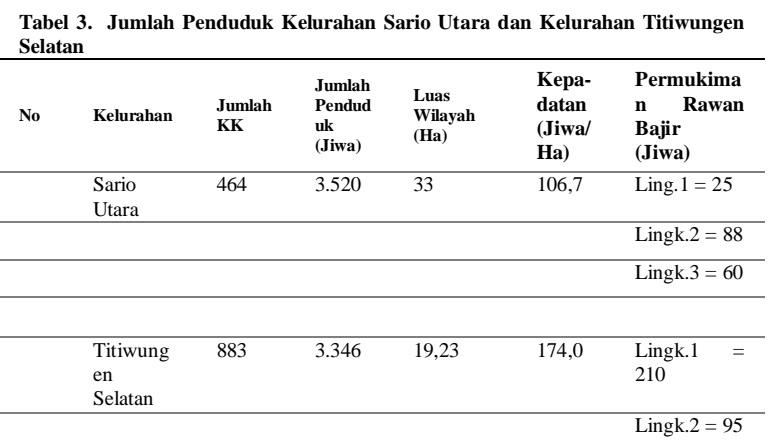

Sumber : Kecamatan Sario Dalam Angka, 2017, dan Survey Primer 2017.

Angka kepadatan penduduk di kedua kelurahan ini, menunjukkan bahwa Kelurahan Sario Utara dan Kelurahan Titiwungen Selatan sudah sangat padat penduduknya, apalagi jika dihitung terhadap luasan terbangun yang ada. Dengan tingkat kepadatan penduduk di atas $100 \mathrm{jiwa} / \mathrm{Ha}$ membuktikan bahwa kedua kelurahan ini bertumbuh dengan pesat.

\section{Tingkat Pendidikan}

Tingkat pendidikan penduduk yang ada di lokasi penelitian hasil survey primer yang dilakukan menunjukkan bahwa yang dominan adalah penduduk dengan tingkat pendidikan SMA dan Perguruan Tinggi ada sekitar $36 \%$ atau berjumlah 560 jiwa (71.98). Sisanya adalah 140 jiwa (9\%) Tamat SMP, dan sisisanya 78 (10) jiwa adalah yang tidak selesai sekolah termasuk yang tidak pernah sekolah. Dilihat dari tingak pendidikan di lokasi penelitian, menunjukkan bahwa Kelurahan Sario Utara dan Kelurahan Titiwungen Selatan mempunyai Sumberdaya manusia yang baik.

4. Mata Pencaharian

Gambaran penduduk di kawasan rawan banjir Sungai Sario bagian hilir sesuai hasil survey primer menunjukkan bahwa $68 \%$ penduduk di loksi penelitian bekerja di sector informal berupa warung, pedagang ikan, buruh, sopir, ketering, kos-kosan, bengkel, sedangkan 22\% adalah karyawan swasta, sisanya $10 \%$ adalah PNS/TNI/Pensiunan pegawai. Jika dilihat aksesibilitas yang ada di wilayah penelitian, sangat mudah bagi masyarakat untuk mengakses tempatnya bekerja, selain itu lokasi tempat bekerja dominan berada di wilayah Kelurahan Sario Utara dan Kelurahan Titiwungen Selatan.
Dari hasil wawancara dengan masyarakat setempat, salah satu yang membuat mereka tetap bermukim di kawasan rawan bajir tersebut karena kedudukan kedua kelurahan ini yang sangat strategis, memudahkan untuk pencapaian keberbagai tempat.

5. Tingkat Pendapatan

Sebanyak $60 \%$ masyarakat di lokasi penelitian memiliki pendapatan setara UMP atau di atas UMP. Hal ini berkaitan dengan mata pencaharian masyarakat yang sudah dibahas sebelumnya. Tetapi masih ada masyarakat yang tingkat pendapatannya di bawah Rp. 500.000 ribu per bulan, sebanyak $8 \%$.

6. Ikatan dan Interaksi Sosial

Ikatan dan interaksi social di di lokasi penelitian sangat tinggi, khususnya untuk kegiatan yang sifatnya keagamaan, karena memang masyarakat yang tinggal di kedua kelurahan ini masyoritas beragama Kristen Protestan. Sehigga bentuk-bentuk interaksi soial seperti persekutuan peribadatan di rumah-rumah sudah menjadi hal yang rutin mereka lakukan setiap minggu. Prosentase penduduk beragma Protestan sebesar 90\% dari toral penduduk yang ada di kawasan rawan banjir bagian hilir Sunga Sario.

7. Jenis Rumah

Jenis rumh yang dibangun masyarakat sebagian besar (64\%) merupakan bentuk dari antisapasi mereka teradap banjir, diantaranya seperti meninggikan tanah rumah, membuat pagar keliling rumah, membuat rumah panggung atau bertingkat. Bahkan ada yang tidak lagi memanfaatkan bagian bawah rumahnya karena sudah berlangganan dengan banjir.

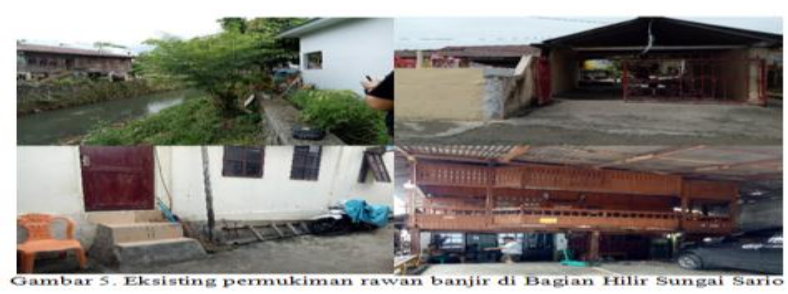

Jika dilihat dari material penyusun bangunan yang ada di lokasi penelitian $80 \%$ rumah terbuat dari beton atau permanen. Bahkan rumah-rumah yang ada di pinggiran sungai adalah rumah permanen.

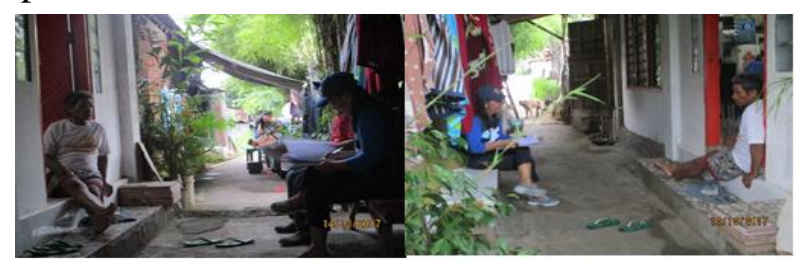

Gambar 6. Rumah Permanen di Tepi Sungai Sario 
8. Sejarah Bermukim

Sejarah bermukim masyarakat di bagian hilir sungai Sario mayoritas $(80 \%)$ di atas 30 tahun. Hal ini menujukkan bahwa masyarakat yang tinggal di bantaran sungai Sario bagian Hilir ini sudah sejak lama dan turun temurun, terbukti dari banyaknya kepemilikan rumah secara warisan atau rumah keluarga. Dengan sejarh bermukim yang sudah sangat lama, menyebabkan ada interaksi yang kuat antara masyarakat dengan lokasi tersebut, meskipun rawan terhadap bencana banjir.

\section{Kebijakan Pemerintah Kota Manado terkait Permukiman di Kota Manado}

1. Perda No. 1 Tahun 2014 tentang RTRW Kota Manado

Menurut Peraturan Daerah Kota Manado No. 1 Tahun 2014, tentang Rencana Tata Ruang Wilayah Kota Manado Tahun 2014-2034, mengarahkan kawasan sempada sungai merupakan bagian dari kawasan perlindungan setempat di Kota Manado, dengan arahan untuk Sungai Sario :

a. Sungai besar di luar kawasan permukiman memiliki sempadan 100 meter di kanan-kiri badan sungai, meliputi Sungai Tondano, Sungai Sawangan, Sungai Bailang, Sungai Malalayang, dan Sungai Sario;

b. Sungai besar di dalam kawasan permukiman tidak memiliki talud sempadan 15 meter di kiri-kanan badan sungai, meliputi Sungai Tondano, Sungai Sawangan, Sungai Bailang, Sungai Malalayang, dan Sungai Sario;

c. Sungai besar di dalam kawasan permukiman memiliki talud sempadan 5 meter di kanan-kiri badan sungai meliputi Sungai Tondano, Sungai Sawangan, Sungai Bailang, Sungai Malalayang, dan Sungai Sario;

2. Perwali No. 55 Tahun 2014 tentang Sempadan Sungai

Menurut Peraturan Walikota Manado No. 55 Tahun 2014, tentang Garis Sempadan Sungai serta Pemanfaatannya di Kota Manado, yang mengatur pemanfaatan daerah semadan sungai berupa pemanfaatan lahan di daerah sempadan oleh masyarakat untuk kegiatan tertentu, sebagai berikut :
a. untuk pemasangan papan reklame, papan penyuluhan dan peringatan, serta rambu- rambu pekerjaan;
b. untuk pemasangan rentangan kabel listrik, kabel telepon dan pipa air minum;
c. untuk pemancangan tiang atau pondasi

prasarana jalan/jembatan baik umum maupun khusus;

d. untuk penyelenggaraan kegiatan-kegiatan yang bersifat social dan kemasyarakatan yang tidak menimbulkan dampak yang merugikan bagi kelestarian dan keamanan fungsi serta fisik sungai;

e. untuk pembangunan prasarana lalu lintas air dan bangunan pengambilan dan pembuangan air;

f. untuk pengembangan khusus tepi sungai bagi kawasan perkotaan.

Jarak garis sempadan sungai yang diatur dalam Peraturan Walikota menurut perwali tersebut untuk Sungai Sario adalah Garis Sempadan 15 meter sungai bertanggul dan 17 meter sungai tidak bertanggul.

\section{Analisis Kerentanan Permukiman Rawan Banjir di Bagian Hilir Sungai Sario \\ Uji Regresi Logistik dengan SPSS 21} menggunakan metode simultan atau metode enter, menunjukkan hasil sebagai berikut :

1. Tabel 4 Case Processing Summary adalah ringkasan jumlah sampel, yaitu sebanyak 50 Sampel, menunjukkan tidak ada data yang hilang (missing cases).

Tabel 4. Ringkasan Jumlah Sampel

\begin{tabular}{llcc}
\hline Unweighted Cases & N & N & Percent \\
\hline \multirow{2}{*}{ Selected Cases } & Included in Analysis & 50 & 100.0 \\
& Missing Cases & 0 & .0 \\
& Total & 50 & 100.0 \\
Unselected Cases & 0 & .0 \\
\hline Total & 50 & 100.0 \\
\hline
\end{tabular}

a. If weight is in effect, see classification table for the total number of cases.

\section{Uji Signifikansi Model}

Untuk mengetahui pengaruh variable independen/bebas terhadap variable depeden/terikat secara bersama-sama didalam model.

Tabel 5. Omnibus Tests of Model Coeffisients

\begin{tabular}{lllll}
\hline & & Chi-square & Df & Sig \\
\hline \multirow{3}{*}{ Step 1 } & Step & 40.597 & 10 & 000 \\
& Mlock & 40.597 & 10 & 000 \\
& Model & 40.597 & 10 & 000 \\
\hline
\end{tabular}


Nilai Signifikansi model sebesar 0,000 karena memiliki nilai lebih rendah dari 5 persen, sehingga disimpulkan bahwa variable bebas yang digunakan, secara bersama-sama berpengaruh terhadap ketepatan keputusan masayarakat untuk "Tetap Bermukim". Atau minimal ada satu variable bebas yang berpengaruh. Presentasi ketepatan kalsifikasi (Percentage Correct), dilihat pada Tabel 5 Classification Table ${ }^{\mathrm{a}}$. Presentsase keputusan model dalam mengklasifikasikan observasi adalah $92,0 \%$. Artinya dari 50 observasi, ada 45 observasi yang tepat pengklasifikasiannya oleh model regresi logistic.

Tabel 6. Classification Tabel ${ }^{\mathrm{a}}$

\begin{tabular}{|c|c|c|c|c|c|}
\hline & \multirow{3}{*}{ Observed } & & \multicolumn{3}{|c|}{ Predicted } \\
\hline & & & \multicolumn{2}{|c|}{$\begin{array}{c}\text { Keputusan Tetap } \\
\text { Bermukimnya atau Tidak } \\
\text { Masyarakat di Bagian Hilir } \\
\text { Sungai Sario yg merupakan } \\
\text { Kawasan Rawan Banjir }\end{array}$} & \multirow[t]{2}{*}{$\begin{array}{l}\text { Percentage } \\
\text { Correct }\end{array}$} \\
\hline & & & $\begin{array}{c}\text { Relokasi/ } \\
\text { Pindah }\end{array}$ & $\begin{array}{c}\text { Tetap } \\
\text { Bermukim }\end{array}$ & \\
\hline \multirow{3}{*}{ Step 1} & $\begin{array}{l}\text { Keputusan Tetap } \\
\text { Bermukimnya }\end{array}$ & $\begin{array}{l}\text { Relokasi/P } \\
\text { indah }\end{array}$ & 12 & 2 & 85.7 \\
\hline & $\begin{array}{l}\text { atau Tidak } \\
\text { Masyarakat di } \\
\text { Bagian Hilir } \\
\text { Sungai Sario yg } \\
\text { merupakan } \\
\text { Kawasan Rawan } \\
\text { Banjir }\end{array}$ & $\begin{array}{l}\text { Tetap } \\
\text { Bermukim }\end{array}$ & 2 & 34 & 94.4 \\
\hline & Overall Percentage & & & & 92.0 \\
\hline
\end{tabular}

3. Uji Parsial dan Pembentukan Model

Tujuannya untuk mencari model yang cocok dan keterpautan yang kuat antara model dengan data yang ada atau dengan kata Model FIT dengan Data. Karena variable independen yang digunakan banyak, maka diseleksi variable independen manakah yang layak masuk model uji multivariate, dengan metode "Enter" dalam regresi ogistik sederhana. Yaitu dengan melakukan satu persatu regresi sederhana antara masing-masning variable independen terhadap variable dependen.

Dari 10 variabel independen yang diuji satu per satu hanya terdapat 3 variabel independen berpengaruh signifika, ini dapat dilihat dari tabel variables in the equation dan lihat nilai sig. Didapat niai signifikan $<0,25$, yang berarti variable Tingkat Pendidikan2, Ikatan Sosial dan Lokasi Pekerjaan" ayak masuk model multivariate, berikut hasilnya.
Tabel 7. Variables in the Equation yang Diuji per Variabel

\begin{tabular}{|c|c|c|c|c|c|c|c|c|c|}
\hline & & B & S.E. & Wald & df & Sig. & $\operatorname{Exp}(B)^{9}$ & $\begin{array}{l}5 \% \text { C.I.for } \\
\text { Lower }\end{array}$ & $\begin{array}{l}\mathrm{r} \text { EXP(B) } \\
\text { Upper }\end{array}$ \\
\hline \multirow{2}{*}{ Step $1^{\mathrm{a}}$} & TktPend2 & -1.537 & 724 & 4.508 & 1 & .034 & .215 & \multirow[t]{2}{*}{.052} & \multirow[t]{2}{*}{.889} \\
\hline & Constant & 1.355 & 397 & 11.667 & 1 & .001 & 3.875 & & \\
\hline
\end{tabular}

\begin{tabular}{|c|c|c|c|c|c|c|c|c|c|}
\hline & & B & S.E. & Wald & df & Sig. & $\overline{\operatorname{Exp}(B)}{ }^{9}$ & $\begin{array}{l}95 \% \text { C.I.fo } \\
\text { Lower }\end{array}$ & $\begin{array}{l}\text { rEXP(B) } \\
\text { Upper }\end{array}$ \\
\hline \multirow{3}{*}{ Step $1^{\mathrm{a}}$} & Ikatan & -4.174 & 1.130 & 4.508 & 1 & .000 & .015 & \multirow[t]{3}{*}{.002} & \multirow[t]{3}{*}{.141} \\
\hline & Sosial & & & & & & & & \\
\hline & Constant & 3.401 & 1.017 & 11.195 & 1 & . 001 & 30.000 & & \\
\hline
\end{tabular}

a. Variabel (s) entered on step 1 : Ikatan Sosial

\begin{tabular}{|c|c|c|c|c|c|c|c|c|c|}
\hline & & B & S.E. & Wald & df & Sig. & $\operatorname{Exp}(B)$ & $\begin{array}{l}95 \% \text { C.1 } \\
\text { Lower } \\
\end{array}$ & $\begin{array}{c}\text { for EXP(B) } \\
\text { Upper }\end{array}$ \\
\hline & $\begin{array}{l}\text { Lokasi } \\
\text { Pekerja }\end{array}$ & 1.522 & .733 & 4.318 & 1 & .038 & 4.583 & 1.090 & 19.266 \\
\hline Step $1^{\mathrm{a}}$ & Constant & .375 & .395 & .915 & 1 & .339 & 1.455 & & \\
\hline
\end{tabular}

a. Variabel (s) entered on step 1 : LokasiPekerja

Berarti ada 3 variabel yang akan diuji, yaitu : Tingkat Pendidikan (Variabel Duammy TktPend2), Ikatan Sosial dan Lokasi Pekerjaan. Langkah selanjutnya adalah memasukkan ketiaga variable di atas dala regresi logistic ganda, dengan hasil sebagai berikut pada Tabel 8 .

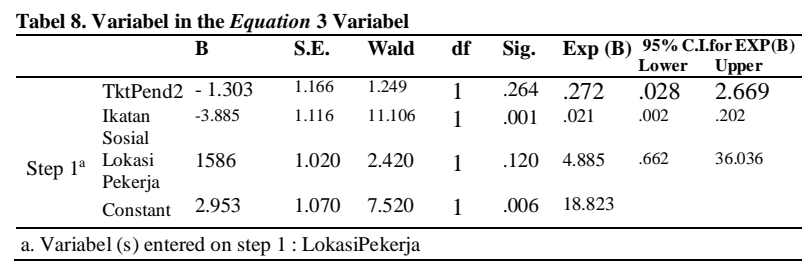

Dari tabel nilai siginifikansi ketiga variabel di atas menunjukkan bahwa hanya variabel Ikatan Sosial yang bisa dimasukkan dalam model karena berpengaruh secara signifikan, yaitu jka nilai $\operatorname{Sig}<\alpha$ , atau nilai Sig <5\%, maka Ho ditolak dan variable Ikatan Sosial yang diuji tersebut masuk ke dalam model. Sehingga model yang terbentuk adalah :

$$
\pi(\mathrm{x})=\frac{\exp (2.935+(-3.885 \mathrm{X} 1 \mathrm{i}))}{1+\exp (2.935+(-3.885 \mathrm{X} 1 \mathrm{i}))}
$$

Yang ditransformasi ke dalam bentuk logit untuk memperoleh fungsi linier, sehingga dapat dilihat hubungan antara variable bebas dan variable terikat tersebut.

$\mathrm{g}(\mathrm{x})=\ln \underline{\pi(\mathrm{x})}=(2.935+(-3.885$ Nilai Ikatan Sosial))

$(1-\pi(\mathrm{x}))$

4. Interpretasi Odds Ratio

Model penelitiannya :

$\mathrm{g}(\mathrm{x})=\ln \underline{\pi(\mathrm{x})}=(2.935+(-3.885$ Nilai

Ikatan Sosial))

$$
(1-\pi(\mathrm{x}))
$$$$
=-0.95
$$

Seperti yang telah didefinisikan sebelumnya bahwa skor 1 merupakan kategori "Tetap Bermukim" dan skor 0 merupakan kategori 
"Relokasi/Pindah", maka hasil prediksi di atas dapat dikategorikan masyarakat di yang tinggal di bagian hilir Sungai Sario akan "Relokasi/Pindah" di kawasan rawan banjir tersebut. Hal ini dikarenakan hasil nilai logit sebesar $-0,95$ tersebut bernilai lebih kecil dari nilai cut-off 0,5. Namun jika nilai logit lebih kurang dari nilai cut-off 0,5, maka hasil prediksi dapat sebaliknya yaitu "Tetap Bermukim". Hasil dari intepretasi adalah sebagai berikut : "Kecenderungan masyarakat di kawasan rawan banjir pada bagian Hilir Sungai Sario untuk tetap bermukim berhubungan positif dengan ikatan sosial. Dimana setiap peningkatan hubungan ikatan sosial masyarakat sebesar satu poin, membuat tendensi/ kecenderungan menetap di kawasan rawan banjir sebesar 0,21 kali. Dengan kata lain : Semakin tinggi tingkat ikatan sosial masyarakat ada kecenderungan untuk tetap bermukim di kawasan rawan banjir. Untuk menjawab Tujuan 2 pada pertanyaan penelitian, yaitu : "Kebijakan penangan permukiman rawan banjir apa yang paling efektif dalam mengatasi permasalahan banjir yang ada di bagian hilir Sungai Sario tersebut", menggunakan analisis deskripsi, dengan melihat beragai kebijakan Pemerintah yang sudah ada, antara lain :

1) Dalam Pedoman Penanggulangan Banjir Pelaksana Harian BAKORNAS Penanggulangan Bencana Tahun 2007:

- program desain dan pembangunan rumah tahan banjir dengan pembangunan rumah tingkat, dan

- pembangunan dengan penggunaan material yang tahan air dan gerusan air.

2) Dalam pedoman pengendalian pemanfaatan ruang di kawasan rawan bencana banjir Dirjen SDA Departemen Pekerjaan Umum sebagai uapaya pengendalian banjir pada kawasan rawan banjir di permukiman khususnya perumahan atau bangunan yaitu dengan mempersyaratkan flood proofing yang antara lain dapat dilakukan dengan cara:

- meninggikan elevasi muka tanah;

- meninggikan elevasi struktur bangunan; dan

- penggunaan bahan bangunan tahan air.

3) Menurut Kodoatie dan Sjarief, (2006), pengendalian banjir dapat dilakukan dengan metode struktur, yaitu dilakukan dengan membangun bangunan pengendali banjir seperti:

- Bendungan, digunakan untuk menampung dan mengelola distribusi aliran sungai. Pengendalian diarahkan untuk mengatur debit air sungai di sebelah hilir bendungan.
- Kolam penampungan (retention basin), berfungsi untuk menyimpan sementara debit sungai sehingga puncak banjir dapat dikurangi.

- Tanggul penahan banjir, penghalang yang didesain untuk menahan air banjir di palung sungai untuk melindungi daerah di sekitarnya.

- Saluran by pass (sudetan), saluran yang digunakan untuk mengalihkan sebagian atau seluruh aliran air banjir dalam rangka mengurangi debit banjir pada daerah yang dilindungi.

- Sistim peningkatan kapasitas sungai dengan pelebaran atau pengerukan alur sungai, bertujuan untuk memperbesar kapasitas tampung sungai dan memperlancar aliran

- Sistim drainase khusus, untuk memindahkan air dari daerah rawan banjir karena drainase yang buruk secara alami atau karena ulah manusia.

\section{KESIMPULAN DAN SARAN}

\section{Kesimpulan}

1. Keputusan masyarakat untuk bermukim di kawasan rawan bajir bagian hilir Sungai Sario terjadi karena dipengaruhi oleh fator-faktor kerentanan terhadap bencana banjir yang melekat pada individu dan lingkungan, yaitu kerentanan social, kerentanan ekonomi, kerentanan lingkungan terbangun dan kerentanan program. Faktor kerentanan yang signifikan mempengaruhi keputusan masyarakt untuk tetap bermukim di kawasan rawan bajir sungai Sario adalah kerentanan sosial tepatnya ikatan sosial, yaitu adanya hubungan kekerabatan yang erat dalam suatu lokasi.

2. Kebijakan Pemerintah yang paling tepat untuk menangani permukiman kawasan rawan bajir bagian Hilir Sungai Sario adalah dengan pembuatan talud penahan sungai atau pengerukan sungai, meskipun hasil persamaan regresi logistic merekomendasikan keputusan masyarakat yang paling tepat adalah "Relokasi/Pindah" dari kawasan rawan bajir tersebut.

\section{Saran}

1. Permukiman masyarakat yang berada di Sempadan Sungai Sario sebaiknya mengikuti arahan RTRW Manado 2014-2034, bahkan Peraturan Waikota No. 55 tahun 2014 yang mengarahkan bahwa wilayah Sungai Sario sepanjang 15 meter dari talud sungai merupakan wilayah sempadan sungai, sehingga rumah- 
rumah yang berada pada kawasan tersebut sangat tepat jika direlokasi. Bahkan rencana pemerintah untuk membuat jalan inspeksi di sepanjang bantaran sungai sebaiknya segera direalisasi.

2. Masyarakat yang tidak masuk dalam wilayah 15 meter kawasan sempadan Sungai Sario, perlu ditata kembali permukimannya terutama yang rumahnya sangat rawan tertimpa musibah banjir dengan melakukan revitalisasi, perbaikan infrastuktur kawasan permukiman seperti saluran drainase lingkungan dan sanitasi.

\section{DAFTAR PUSTAKA}

Anonim, Dep PU. 1994. Teknologi Pengendalian Banjir di Indonesia. Direktorat Sungai, Ditjen Pengairan.

Arahan Kebijakan Mitigasi Bencana Perkotaan di Indonesia. (2002). Bakornas PBP.

Asdak, 2002. Hidrologi dan Pengolahan Daerah Aliran Sungai. Gajah Madah University Press. Yogykarta.

Asrininggrum, Gunawan, 1998. Zonasi Tingkat Kerentanan Banjir Menggunakan Sistem Informasi Geografis (studi kasus Daerah Istimewa Jogjakarta).[skripsi]. Fakultas Geografi Universitas Gajah Mada.

Budiharjo, Eko, 1997, Arsitektur dan Kota Di Indonesia, Bandung: Alumni.

Budihardjo, Eko dan Sujarto Djoko. 1998. Kota yang Berkelanjutan (Suistinable City). Jakarta: Direktorat Jenderal Pendidikan Tinggi Departemen Pendidikan dan Kebudayaan.

Budiharjo, Eko dan Sudanti Hardjohubojo 2009, Wawasan Lingkungan Dalam Pembangunan Perkotaan, Bandung, Alumni.

Burthos, Basir. 2001. Manajemen Sumber Daya Manusia, Suatu Pendekatan Makro. Jakarta: Bumi Karsa.

B. Wignyosukarto, 2007, Pengelolaan Sumberdaya Air Terpadu dalam Upaya Pencapaian Tujuan Pembangunan Millenium 2015, Pidato Pengukuhan Guru Besar FT UGM.

Duwi Priyatno, 2013 Analsis Korelasi, Regresi dan Multivariate dengan SPSS, Penerbit Gava Media Yogyakarta.
Hadari, Nawawi, 1996 Metode Penelitian Bidang Sosial, Jogyakarta, Gadjah Mada University Press.

Halim, D.Kurniawan. 2008. Psikologi Lingkungan Perkotaan. Jakarta: Bumi Aksara.

Haryono, Paulus. 2007. Sosiologi Kota Untuk Arsitek. Jakarta: Bumi Aksara.

Hasan. 2002. Pokok-Pokok Materi Metodologi Penelitian dan Aplikasinya. Jakarta: Ghalia Indonesia.

Ibrahim, Linda.D. 2005. "Kehidupan Sosial Budaya Kota”, dalam Soegijoko, Budhy.TS dkk (eds). Bunga Rampai Pembangunan Kota Indonesia dalam Abad 21, Konsep dan Pendekatan Pembangunan Perkotaan di Indonesia. URDIYSS-Jakarta: Lembaga Penerbitan Fakultas Ekonomi, Universitas Indonesia, hal. 199-216.

Kodoatie,Robert. J, dan Sugiyanto. 2002. Banjir, Beberapa Penyebab dan Metode Pengendaliannya Dalam Perspektif Lingkungan. Yogyakarya: Pustaka Pelajar.

Kodoatie,Robert. J, dan Sjarief,Roestam. 2006. Pengelolaan Bencana Terpadu, Banjir, Longsor.

Lasino, 2002. Pengaruh Genangan Terhadap Bangunan. Makalah, Disajikan dalam seminar Dampak Kenaikan Muka Air Laut Pada Kota-Kota Pantai di Indonesia, Bandung 12-13 Maret 2002.

Moh. Nazir, Metode Penelitian, 2005, Ghalia Indonesia.

Patilima Hamid 2007, Metode Penelitian Kualitatif, Bandung,Alfabeta.

Pedoman Pengendalian Pemanfaatan Ruang di Kawasan Rawan Bencana Banjir, 2009, Dirjen Sumber Daya Air Departemen Pekerjaan Umum.

Permen PU No. 63/PRT/1993 tentang Garis Sempadan Sungai, Daerah Manfaat Sungai, Daerah Penguasaan Sungai dan Bekas Sungai.

PP No. 38 Tahun 2011 tentang Sungai.

Peraturan Walikota Manado No. 55 Tahun 2014, tentang Garis Sempadan Sungai serta Pemanfaatannya di Kota Manado. 
Prijana, 2005, Metode Sampling Terapan, Bandung: Humaniora.

Perda No. 1 Tahun 2014, tentang RTRW Kota Manado 2011-2031.

Sandjaja, B dan Albertus Heriyanto. 2006. Panduan Penelitian. Jakarta: Prestasi Pustaka.

Soegijoko, Budhy.TS dkk (eds). Bunga Rampai Pembangunan Kota Indonesia dalam Abad 21, Konsep dan Pendekatan Pembangunan Perkotaan di Indonesia. URDI-YSS-Jakarta: Lembaga Penerbitan Fakultas Ekonomi, Universitas Indonesia.
Silas, John. 2006. "Beberapa Pemikiran Dasar Tentang Perumahan dan Perkampungan" dalam Budihardjo, Eko (ed). Sejumlah Masalah Permukiman Kota. Bandung: Alumni, hal. 241-252.

Singarimbun, Masri dan Sofian Effendi. ed. 2006. Metode Penelitian Survei. Jakarta. LP3ES.

UU Nomor 1 Tahun 2011 tentang Perumahan dan Kawasan Permukiman.

Yamin, Sofyan \& Heri Kurniawan. 2014. SPSS Complete Teknik Analisis Statistik Terlengkap dengan Software SPSS, Edisi 2. Jakarta: Salemba Infotek. 